This item was submitted to Loughborough's Research Repository by the author.

Items in Figshare are protected by copyright, with all rights reserved, unless otherwise indicated.

\title{
Identity, friendship and sociality
}

PLEASE CITE THE PUBLISHED VERSION

https://uk.sagepub.com/en-gb/eur/the-sage-handbook-of-drug-alcohol-studies/book245050\#9781473912427

PUBLISHER

SAGE Publications Limited

VERSION

AM (Accepted Manuscript)

PUBLISHER STATEMENT

This work is made available according to the conditions of the Creative Commons Attribution-NonCommercialNoDerivatives 4.0 International (CC BY-NC-ND 4.0) licence. Full details of this licence are available at: https://creativecommons.org/licenses/by-nc-nd/4.0/

\section{LICENCE}

CC BY-NC-ND 4.0

\section{REPOSITORY RECORD}

Thurnell-Read, Thomas P.. 2019. "Identity, Friendship and Sociality". figshare.

https://hdl.handle.net/2134/24524. 


\section{Identity, Friendship and Sociality}

Thurnell-Read, T. 2016. 'Identity, Friendship and Sociality' in Handbook on Drug and Alcohol Studies: Social science perspectives, Koling, T., Thom, B. and Hunt, G. (eds). London: SAGE.

ISBN: 978-1446298664

\section{Dr Thomas Thurnell-Read}

Department of Social Sciences

Loughborough University

Loughborough

LE11 3TU, UK

Email: t.thurnell-read@lboro.ac.uk 


\title{
Identity, Friendship and Sociality
}

\author{
Thomas Thurnell-Read
}

\section{Introduction}

This chapter explores how drug and alcohol consumption relates to identity, friendship and sociality and starts with the observation that the conditions under which drugs and alcohol are consumed are inescapably socially defined. Even solitary consumption takes place in the context of societal expectations that often construct normative boundaries separating acceptable from unacceptable styles and settings of use. Indeed, a particularly fruitful strand of work in the social sciences has been to foreground the social context of intoxication and drunkenness as being integral to understanding the motivations, subjective experiences and identities of users (Jayne et al., 2006; Hunt et al., 2010). While this growing body of research does not seek to undermine valued explanations of pathology, addiction and an array of physical and psychological harms that might arise from drug and alcohol use, they do, as this chapter will demonstrate, bring to the fore the inescapably social nature of alcohol and drug use analysis.

Since the 1990s, academic research on drug taking and drinking cultures have made a turn towards the inclusion of the social context in explanations of why the consumption of such substances might be seen as pleasurable and desired by those who participate in spite of prohibition, regulation and wider long-standing discourses of risk and harm. As such, the social pleasures and 
potential benefits of drug use have long been, and in many ways still remain, 'the great unmentionable' of drug and alcohol research (Hunt and Evans, 2008). These benefits can be found in the immediate moment through feelings of camaraderie, intimacy and mutual support (e.g. Niland et al., 2013), as well as in the longer term by building lasting group loyalties and through shared experiences which lay the foundations for future narrations of identity and group belonging (Blackshaw, 2003).

This move has taken place in spite of what, in many countries, has amounted to an intensification of media and policy discourses that position alcohol and drugs as a societal problem to be blamed on the moral failures of individuals (Plant and Plant, 2006; Taylor, 2008). Against this backdrop, social science scholars working on drink and drugs have trod a precarious path in seeking to acknowledge the pleasurable, socially positive, features of intoxication. One feature of this move has been to find order in the apparent chaos of heavy 'binge' drinking and to explore how the consumption of alcohol sustains complex rituals which unite the individual with the group. Both Tomsen (1997) and Campbell (2000), for example, highlight in their work how the apparent disorder and disarray of drinking settings, while disparaged by external commentators, contains its own internal logic which gives rise to social pleasures for participants and for the display and performance of identity and belonging. Likewise, in their influential paper Measham and Brain (2005) demonstrate that through 'determined drunkenness' aspects of drinking previously conceptualised as negative or risky emerged as desired aspects of the drinking experience, integral to the sense of fun, playfulness and release 
desired by young drinkers. In these and other examples to be explored below, a challenge presented to the researcher has been both a methodological and epistemological one; how can the experience of collective drug use or heavy alcohol consumption by adequately captured and analysed in order to reveal and give due recognition to pleasurable aspects of either drinking or drug taking which are often embodied in complex ways? Similarly, how might these pleasures and benefits be presented whilst still giving due regard to the potential and actual harms of substance (mis)use?

In this sense, the 1990 s is identifiable as a seminal decade in work on drug and alcohol use in the social sciences and signaled a new willingness to break from simplistic discourses of deviance and pathology borne solely by the individual by instead foregrounding the significance of friendship, relaxation, excitement, fun and playfulness. Notably, it was the emergence of the rave scene and clubbing in Britain and the USA around this time that prompted a number of studies of ecstasy use where exactly these concerns were brought to prominence (Thornton, 1995; Saunders, 1996; Parker et al., 1998; Malbon, 1999). The strength of these studies, perhaps made possible by the relative novelty of ecstasy both as a substance and as a topic of academic research, was that drug use was a prominent but integrated feature of overlapping concerns of friendship, social relations, and embodied feelings of well-being, trust and communality. As such, Malbon (1999: 3) observed that the experience of clubbing was 'constituted through the practices, imaginations and emotions of the clubber themselves' rather than abstracted and often moralising media or public order discourses. Notably, as Parker et 
al. (1998: 7) noted, ravers and ecstasy users came from different social classes and from both sexes, making blanket condemnation of pathology more difficult.

There has also been a move towards a more complex explanation of how individuals might become integrated into social groups where drug or heavy alcohol use is a prominent feature. The past dominance of a narrative of 'peer pressure' emphasising a descent or indoctrination into a 'deviant' subcultural or lifestyle has been challenged. While the role of the peer group has long been associated with decisions to use certain substances, this has often been framed as a 'peer pressure' scenario involving initiation into a deviant lifestyle (Foster and Spencer, 2013). As such, the most accomplished work on drink and drugs from this period 'tends to concentrate on the theoretical goal of moving beyond pathologizing alcohol consumption in order to present the everyday social relations and cultural practices bound up with drinking' (Jayne et al., 2008: 453). Pilkington (2007: 222) has argued convincingly for the need to address the more complex nature of drug and alcohol use within friendship groups by suggestion that 'the friendship group is thus better understood as providing a set of reference points underpinned by bonds of emotionality and mutual accountability about acceptable and unacceptable drug use and a secure and supportive environment in which to enact the ensuring drugs decisions'. Similarly, Cullen (2010: 493) seek to problematise the uncritical peer pressure model and instead give full understanding of 'a wider process of reciprocity, and the construction and negotiation of individual and group gendered, classed and generational identities'. Emerging from this critical 
process is a vibrant field of research - although not one without limitations, some of which will be addressed in the concluding section - where a range of contemporary studies are revealing insights into the intimate lives of individuals and groups who drink alcohol or take drugs for pleasure and for a number of distinctly social benefits (Griffin et al., 2009; Vander Ven, 2011).

The chapter therefore argues that the consumption of drugs and alcohol is inherently social and relational and best analysed not as an isolated and problematic behaviour of disparate, possibly deviant, individuals but as a social practice constituted and (re)formed by and through friendships, groups and spontaneously formed acquaintances. This is not to say that the individual can or should fade from analytical view. Rather, it is to suggest that a wealth of scholarship now demonstrates the value of giving due regard to the pleasures, emotions and feelings that animate much drug and alcohol use at its core, which we might locate at the intersection of individual and group identities. As such, when one participant in Chatterton and Hollands' (2002: 109) study of nightlife in British cities explains that 'it's great to be in one of those groups. It feels really powerful in a horrible sort of way...you are accepted you know' it speaks of the considerable social function of alcohol to bind the individual to the group and to produce an array of emotions and feelings such as acceptance, belonging and power.

The chapter aims to offer a review of recent research which has intensified the centrality of identity, friendship and sociability to understandings of drug and alcohol use. Following this brief introduction, the chapter will examine the 
role played by the consumption of drugs and alcohol in constructions of individual, group and national identity. In particular, the case of the consumption of the stimulant khat amongst Somalis in East Africa (Beckerly and Nuur, 2005; Carrier, 2005) and within the European Somali diaspora (Griffiths et al., 1997; Osman and Söderbäck, 2011), will be used to demonstrate the complicated interplay of substance and identity which intersects gender, ethnicity, social class, nationality, age and familial facets of identity construction. The following section will then draw on a range of recent empirical studies to pinpoint some of the ways in which alcohol and drug use are constituted socially. The section will highlight eight different, yet often overlapping, features of the sociality that emerges from and around drug and alcohol consumption. In concluding, the chapter brings these themes together to reflect on the importance of understanding the embodied, affective and - at times what can only problematically be called - positive aspects of drug and alcohol use.

\section{Identity}

Rather than pre-empt the work undertaken elsewhere in this volume (for instance, Moloney and Hunt on Gender; Sanders on Ethnicity and Bancroft on Social Class), this section will aim to illustrate how drug and alcohol use are in numerous ways important constituents of the identities of those who consume them and, further, that these identities are constructed and negotiated within the settings and practices of their consumption. Rather than attempt to delineate and separate examples of how alcohol and drug use might relate to, 
for example, gender, sexuality, social class or ethnicity, I will here aim to illustrate how alcohol and drug consumption can be bound up with intersecting and overlapping facets of personal, group and national identity. As such, two recent studies, both of which focus on practices of drinking alcohol as an integral part of sports participation, illustrate how identity is performed and negotiated through alcohol consumption within specific social settings.

In Joseph's (2012:161) ethnographic study of older Caribbean men's alcohol consumption at cricket grounds in Canada we see how 'drinking at the cricket ground is central to their aged, gendered, classed and national identities'. Here, Caribbean migrants bring with leisure practices, principally the specific sport of cricket and a particular style of public ritualised drinking, which are reconfigured in the diaspora as potent markers of ethnic identity. Additionally, while the cricket ground itself is coded as a specifically masculine social space, with women and children being typically excluded, the drinking of alcohol functions as a means of performing masculinity and, further still, a specifically aging masculinity. Indeed, many of the older men might have had the transition from active participant to relatively less active spectator, brought on by age and diminishing physical capacities, eased by the consumption of alcohol as a substitute activity and a replacement means to publically display their masculinity.

Similarly, Fletcher and Spracklen (2013) illustrate how the importance placed on post-match drinking of alcohol in British cricket clubs constructed lines of 
inclusion and exclusion for British Muslim male cricket players. Thus, while British Muslim players might be fully engaged participants of the sport itself they are, by their religious prohibition of alcohol consumption, excluded from participation in the wider social life of the club. While some aspects of 'Britishness' and 'masculinity' are accessible through participation in the sport, others are inaccessible due to the social significance placed on (heavy) alcohol consumption in underlying the dominant sporting white masculine identity. Again, we see how alcohol can play a vital constitutive role in the construction and negotiation of identity. As is addressed below, alcohol can bind the individual to a group as much as it can exclude others.

Similar interplay and intersection of identities can be observed in the growing body of research into the use of khat as a recreational drug within certain sections of the Somali community. Khat, also known as miraa, is the leaf of a plant grown in Eastern Africa which is chewed by users for its mild narcotic effects. Khat might have a medicinal use, cultural use in ceremonies, a social use in leisure spaces, and a functional use during work by, for instance, providing lorry drivers with the stamina and attentiveness required for long trips (Carrier, 2007). Notably, these effects are seen as distinctly social:

'Chewers report an immediate emotional effect of euphoria, which increases the sense of well-being and can facilitate social interaction. Indeed, khat seems to greatly exacerbate the chewers' urge to express themselves, albeit at the expense of their listening skills. The initial stage of a typical khat-chewing session is therefore characterized by a 
din of voices, with all attendant speaking excitedly and at the same time' (Anderson et al., 2007: 14).

As with other drugs, learning to consume khat and appreciate its effects, as well as mitigate against its negative impacts, can be seen as a social process. As Carrier (2007: 7) states, 'one learns to appreciate miraa's effects in the company of friends, one learns terms for miraa that have strong cultural resonances, and chewing sessions have great social significance' (Carrier, 2007: 7).

Khat use has become closely associated with Somalis both in East Africa and within the Somali diaspora in Europe (Beckerley and Nuur, 2005). With khat use entering Europe with East African Migrants, the production and distribution of the substance now amounts to a global supply chain (Anderson et al., 2007). In this context, there are suggestions that khat use is heightened amongst Somali communities in Europe and takes on an increased significance as a marker of cultural identity and becomes the focus of community sociability, at least for men (Griffiths et al., 1997; Carrier, 2005). Similarly, in their study of khat use amongst Somalis in Sweden, where the substance has been prohibited though nonetheless still extensively used since 1989, Osman and Söderbäck (2011: 216) noted how khat was seen as 'a medium for cultural and community cohesiveness' that benefited individual users by facilitating conversation, relaxation and bonding. The sociable setting of khat use would provide a stage for the discussion of topics ranging from football, community gossip, to job opportunities and news of the latest 
weddings 'back in Somalia' (Carrier, 2005). Indeed, chewing khat provides migrants, and their offspring, with 'tangible links to Africa' (Carrier, 2005: 15).

A further layer of complexity can be added to this brief description by noting the gendered nature of khat consumption. While khat is consumed by both Somali men and women, the latter are more likely to do so within the confines of the home as opposed to the more public setting of the 'mafrish', a café-like setting in which men consumer khat and secondary services such as tea are provided. Further, several studies have noted that Somali women more likely to engage in prevention and to position excessive khat use as a threat to families and community cohesion (Osman and Söderbäck, 2011; Nordgren, 2013). Indeed, perhaps the loudest call for the prohibition of khat in the UK (which came into force at the time of writing, in June 2014) has been its perceived negative impact on the employment chances of young Somali men where there is a fear that while khat might usefully fill the spare time enforced by unemployment, it also inhibits social mobility and integration.

Khat is therefore by turns depicted as both a benefit and a threat to the individuals and the community in terms of maintaining culture and binding individuals, through their everyday habits and practices, to the community but also, at the same time, often perceived as a threat and a danger. As with the studies by Joseph (2012) and Fletcher and Spracklen (2013) discussed at the start of the section, looking at the case of khat consumption illustrates a number of themes central to the focus of this chapter. Firstly, the benefits of khat are largely defined as being social and as encouraging sociability 
through candid talk and conviviality. Pushing beyond this, we see how khat use is framed by wider constructions of identity in relation to ethnicity, gender

and social class. Again, we see that there is no straightforward way to disaggregate these components of personal and group identity. Rather we must locate drug or alcohol use within these intersecting strands of identity. It is through the social interaction that is a central feature of drug and alcohol consumption that identity is negotiated and performed.

\section{Friendship, Bonding and Sociability}

Having explored the ways in which alcohol and drug use are entwined with complex constructions and performances of identity, the remainder of this chapter will now consider more specifically how this relates to sociality in the form of friendship, interpersonal bonding and intimacy. While studies have established that there is a long history of links between drinking rituals (Wilson, 2005), popularity and social acceptance (for example, Balsa et al., 2010), a more detailed account may be offered as to how this sociality plays out in practice. The section draws on the considerable array of empirical studies that have, in the last decade or so, brought to the fore the social nature of drug and alcohol consumption and, in particular, the role of peer groups, friendships and bonding rituals. While previous studies might have sought to isolate individual users, there is now more acceptance of how substance use is 'intricately woven into friendship' (Foster and Spencer, 2013: 224). To understand such we must explore the affective aspects of drug use within friendships that cultivate feelings of trust, belonging and intimacy. 
Recent years have seen young people become the focus of much research on the role of alcohol consumption. In recent work in New Zealand by Niland et al. (2013:531 original emphasis) it is noted that for young people drinking can be understood as 'a shared social practice that is pleasurable and undertaken within friendships'. Likewise, a review of over 80 studies of young people's motivations to consume alcohol found a common narrative based around sociability and drinking as a means to relax and bond with friends (Kuntsche et al., 2005). Such studies have highlighted how, in numerous ways, it is remiss to attempt an understanding of drug or alcohol use without paying due attention to interpersonal relationships and the relational interactions they give rise to and support. While by no means intended as an exhaustive list, I shall here outline eight ways in which drug and alcohol consumption encourages, facilitates or in other ways plays a prominent role in friendships, bonding rituals and, most generally, sociality.

Spaces and Times Suitable For Sociality to Take Place

Alcohol and drug use can have a significant influence on the time and location of social interaction and both the formation and maintenance of friendships. Indeed, much drinking can be highly ritualistic in nature (Beccaria and Sande, 2003), bringing people together at specified times and in particular places. Wolburg and Treise (2004) noted in their study of heavy drinking in North American that alcohol played an important ritual function in designating times and locations for collective drinking. As such, certain bars would be 
associated with particular styles and intensities of drinking, with particular drinking partners, and with particular activities such as watching either live or televised sports matches. Social drinking was also found to be temporally structured with key moments being marked by the coming together of friends and acquaintances to share in a Friday night drinking session to mark the end of the working week or, for students, occasions such as the end of the midterm examination season.

It should also be worth noting that these spaces are often heavily gendered (e.g. Leyshon, 2008; Waitt et al., 2011). Crawford (2009), for instance, observes that the convergence of sport and alcohol provide places where the consumption of both sport and alcohol becomes a highly gendered collective activity. Women may be overtly or implicitly excluded. As Driessen (1992: 73) has observed in relation to the Spanish taverns in Andalusia, drinking spaces can be seen as 'a social context for the creation and maintenance of friendship and the celebration of masculinity'. Similarly, Campbell (2000) suggests that in New Zealand the rural pub has long been a stage upon which a particular masculinity is enacted through ritualistic and, notably, collective public drinking practices.

These themes are well identified in Anne Allison's (1994) ethnographic study of Japanese 'hostess clubs', where paid female staff serve all male groups of officer workers and 'play the part' of 'hostess' by pouring drinks, laughing at jokes and helping the customers to 'feel like a man'. The hostess plays out a role which functions to support the identity of both individual customers and 
the collective group. Through her interaction with the group, through serving alcohol and encouraging drunken disinhibition, she works to literally 'create a group' (Allison, 1994: 65) out of the individual workers. Such complex social interactions belie any easy distinctions between individual/collective or causation based explanations. Alcohol, in particular, provides the space and time for this coming together of disparate individuals.

\section{Shared Experiences Brought About By Substance Consumption}

Perhaps the most prominent quality linking alcohol and drug use to sociability and friendship is that consumption can be a shared activity which is conducted rarely by individuals alone but by groups. Indeed, a key feature of Measham and Brain's (2005) influential discussion of 'determined drunkenness' is that achieving a state of advanced intoxication is, in and of itself, a desired and ritualistic activity for many young people. It has recently been noted that 'for young people, the pleasures of drinking tend to be shared ones' (Brown and Gregg, 2012: 361). Further still, a range of secondary activities commonly pursued as part of drug or alcohol consumption offer shared experience though which individuals might bond and form social ties. Playing or watching sport, dancing, talking, gambling or playing card and dice games are all sociable activities which frequently take place alongside the consumption of alcohol. This sense that alcohol can be a pleasurable enhancement to social situations and leisure activities in allowing people to share pleasurable experiences together is readily exploited in industry marketing and is most apparent in the 'buddy' or 'best mates' narrative 
identifiable in numerous beer commercials and marketing campaigns (Wolburg and Treise, 2004).

While this theme can often emerge from the accounts of research participants in a rather matter-of-fact way, a good example being the oft used phrase 'having a laugh with friends' (Parker et al., 1998: 157), it is in itself an insight which necessitates further unpacking. In both stag parties (Thurnell-Read, 2012) and bachelorette parties (Montemurro and McClure, 2005) while the drinking of alcohol is one of the main activities pursued by the group, a range of secondary activities are also pursued. Drinking games, for example, provide a common group focus, a competitive activity, encourage involvement and 'foster a low-key and enjoyable atmosphere' where 'inhibitions tend to be reduced, facilitating a sense friendship and camaraderie' (Borsari, 2004: 36). Many such drinking games also have as a specific feature of making individuals, or the entire group, drink more quickly and in greater quantities than they might otherwise.

While this is often a positive and directly desired element of the substance use, risks and dangers either of the substances themselves or, more commonly, those which the situation in which intoxication takes place gives rise to can foster displays of care and protection between friends. A recent study by MacClean and Moore (2014) of young people's drinking experiences in Australia observed that while the urban environment presented risks, most notably through interpersonal violence, those risks also in some ways proved 
beneficial in that friendships were strengthened around a mutual need for friends to protect and support each other.

Stories upon Which Status Can Be Built and Future Bonding Based

While alcohol or drug use provides a shared experience through which friends and acquaintances can bond, the social implications of this are not solely limited to the moment of consumption. Indeed, several recent studies have illustrated how the incidents of the night of heavy drinking provide stories which circulate between friends long after the event (Sheehan and Ridge, 2001; Griffin et al., 2009). The telling of drinking stories can therefore support the status of the individual but also work to build and sustain group loyalty. As Fry (2011: 68) observes 'story-telling reinforced the value of drinking experiences beyond the individual's experience creating a greater sense of cohesion, intimacy and bonding with peers'. Similarly, in their study of young Danish tourist's narrations of drinking escapades in a Bulgarian holiday resort, Tutenges and Sandberg (2013: 542) note the importance of this collective nature of drinking stories which were 'not a long recital performed by one single person' but 'constructed collaboratively and proceeded in a flow of statements, questions, pauses for thought and finally, laughter that dissipated the tension'. Being part of and party to these stories and their telling therefore represents a significant social tool for cementing friendships and group identity. 
Notably, the narration of drinking stories takes on a normative quality where appropriate ways of drinking and behaving whilst drunk are expressed, negotiated and standardised. Such narratives may, however, form an alternative account where spontaneity, irreverence and risk taking are valorised. For instance, Hackley et al. (2013), turning the literary analysis of Mikhail Bakhtin to focus group recollections of young British people's drinking stories, explore the carnivaleque qualities of narratives of drunkenness and intoxication. Such accounts are characterised by satirical laughter, the spectacle of surreal or unusual events and the subversion of social order, rules and roles.

Further still, the emergence of social media has provided a new inflection to this centrality of drinking stories to collective experiences and recollections of intoxication. Thus, in recent years there are indications that sites such as Facebook and Twitter are allowing a boarder circle of friends and acquaintances to share in drinking via vicarious consumption of drunkenness (Brown and Gregg, 2012; Niland et al., 2013).

\section{Sharing Substances as a Symbolic Marker of Friendship}

Through their commodity value, drugs and alcohol can take on a symbolic quality and a social function where their exchange can communicate friendship and reciprocity between individuals and within groups. So to, amongst clubbers the sharing of drugs such as ecstasy and 'poppers' as well as other commodities like chewing gum and bottled water when clubbing 
symbolises a wider sense of sociability and openness (Moore and Miller, 2005). This might be heightened when bonding centres around prohibited substances, the very act of sharing drugs together can itself affirm feelings of trust and support between friends (Foster and Spencer, 2013). Social groups might place ritualistic importance on the buying of 'rounds' of drinks, ensuring that all group members receive and consume specific drink at specific moments and, further still, that all group members drink at the same time and aim to achieve similar levels of intoxication. During British premarital stag tours in Eastern European cities, it is common for drinks to be bought from a communal fund or 'kitty' to which all group members have contributed (Thurnell-Read, 2012).

In their study of 44 drug users in Florida, USA, Belackova and Vaccaro (2013: 296) identified sharing and reciprocity to be central to marijuana use between peers, where 'the decision to share marijuana is a symbolic gesture that is selectively made to enact and affirm a friendship identity between two or more people'. Further, non-reciprocating friends were found to be at risk of being cut out of the peer circle. A similar symbolic value of substance sharing was noted by Cullen in her study of young women's smoking practices in Britain. She noted that 'young women, via the sharing and exchange of cigarettes, performed and produced a range of ways of 'doing girl' to secure their place within their friendship groups (Cullen, 2010: 492).

Easing of Pressures and Social Anxieties and Brought On By Social Situations and Interactions 
In numerous studies, both alcohol and various drugs have been shown to give those who consumer them a feeling of confidence or easing of general social anxieties. Noting that many studies of young women's drinking have tended to overplay or at least take for granted the apparent centrality of intimacy to drinking amongst female friends, Stepney (2013) instead reminds us that alcohol plays a role in easing social anxiety and facilitating 'small talk'. There is also some evidence that, for many young men, alcohol consumption is seen to boost social confidence, particularly in relation to talking to and 'picking up' women (de Visser and Smith, 2007).

While the ability of alcohol to bestow confidence, or so called 'Dutch courage', upon those who consume it has a long cultural lineage, we might here focus on how that confidence allows individuals to partake in particular social settings and, within those settings, to play certain social roles appropriately. As such, two recent studies of drinking amongst American students (Vander Ven, 2011; Chrzan, 2013) have found that alcohol allowed students to negotiate competing demands of balancing high academic achievement with a rich social life. Students used alcohol consumption not only to unwind after class, following assessments and at the end of term but to manage their selfidentity and the transformation between a studious, academic role, and an extrovert and sociable identity. In both cases, the highly sociable atmosphere of the college campus, for many, seemed to necessitate alcohol consumption in order to live up to expected social norms relating to being a fun, confident and sociable and to ease feelings of anxiety or timidity. 
Deindividualisation

While it is clear that alcohol and drug use can play an important role for individuals in the constitution of their personal identity, a striking feature of many studies in this field is the prominence of discourses of deindividualisation and group identity formation. Thus, alcohol or drug use might offer a way for an individual to 'open up', to be more sociable and to be less self-orientated. American college students attending spring break celebrations in costal resorts across America and the Caribbean have been shown to drink more alcohol and to be more likely to experiment with drugs or partake in risky behaviours such as unprotected sex by entering a state of 'situational disinhibition' (Josiam et al., 1998; Sönmez et al., 2006). The situation, and the expected 'script' of spring break hedonism, allow the participant to let go of individual concerns or inhibitions.

Similarly, ecstasy is specifically associated with increased empathy, making users more communicative and less self-orientated (Saunders, 1996) and has been shown to bring on a feeling of openness and to make users feel less judgmental and less self-conscious (Hunt and Evans, 2008). In Thornton's (1995) study, a reoccurring theme amongst clubbers was that the effects of taking ecstasy, in combination with the visual and aural spectacle of the night club, allowed participants to 'lose' themselves in the music and experience (Thornton, 1995). 
More recently, a number of studies have noted that heavy drinking amongst young people might increasingly be seen as a means of release from pressures to construct and present a coherent and disciplined individual identity to the world in contemporary societies. The 'passing out stories' of young British drinkers have been explored, revealing the evident pleasure taken as 'a sort of 'time out' from the world of rational civilized individual subjectivity and self-control' (Griffin et al., 2009: 471). Indeed, the ability and willingness to let go of oneself appears to be a new demand on many young people where the public display of self-destructive drinking is a sought after and intended element of the experience of intoxication (Thurnell-Read, 2011; Brown and Gregg, 2012). Thus, through drunkenness and intoxication individuals are able to show to friends and the wider world that they do not take themselves too seriously and are willing to perform a lack of restraint which seems to bear increasingly cultural stock in a wider atmosphere if individualisation (see Smith, 2014).

\section{Group Cohesion and Solidarity}

While drugs and alcohol might be used by individuals as a means of opening up and becoming more sociable and gregarious, a further theme emerging from many studies is that consumption of alcohol or drugs can make groups, clubs and social circles more coherent and defined. Such has been observed in a number of different contexts. Drinking games and rituals in Norway and Italy carry the social function of 'cementing friendships and developing a community spirit' and 'enhancing group conformity' (Beccaria and Sande, 
2003: 104), while drinking alcohol is important for establishing solidarity amongst young gang members in the San Francisco Bay area (Hunt et al., 2005). Zhou et al. (2013: 11) identified collective drinking of alcohol as an important feature of sports team participants where alcohol was commonly used to foster 'a sense of camaraderie and cohesion'. Indeed, participation in some social clubs or groups may expressly necessitate alcohol consumption. Dempster's (2011), for example, research at a British university found that sports teams in particular often treated alcohol consumption as a prerequisite of membership, although interestingly such conformity to expected excesses of student drinking was also cited as a sign of weakness by others.

Again, the premarital stag and bachelorette party are occasions where group cohesion is expected and where alcohol is seen as a primary facilitator of developing a collective identity for the group (Thurnell-Read, 2011, 2012; Montemurro and McClure, 2005). As noted above, all members of the group may be required to drink specific drinks at specific times. Further still, there is an implicit understanding at such events that all group members will drink alcohol and that, to some extent, all group members will become active participants in drunken activities and incidents.

Boundary Marking and Exclusion

Strong social groups frequently operate to assert relatively fixed boundaries and, often, involve the visible and overt exclusion of others. Further, a more subtle process of distinction, where in-group members frame their individual 
or collective identity in relation to real or perceived out-groups, may be apparent. This might include marking boundaries between different types of users of the same substance, between users of different substances, or between users and non-users. For example, in Thornton's (1995) study, British clubbers made common reference to a perceived mainstream from which they set themselves apart. Here, the musical taste, styles of dress and modes of behaviour of others were all invoked in contrast to those of the clubbers themselves. However, it was in the differences between intoxicants of choice that notably formed a dividing line, with clubbers framing their use of ecstasy in opposition to the heavy drinking of alcohol seen in the more mainstream British night-time leisure venues. Similarly, emerging from Hunt et al.'s more recent $(2010: 193,198)$ work on club based drug taking amongst American young people, many clubbers readily expressed anti-alcohol views where drunk individuals were perceived by clubbers as anti-social in being 'pushy' and 'volatile' while drugs such as MDMA were represented as more social in encouraging conviviality, playfulness and sociability.

Friendship groups over time may change with particular individuals, prompted by their drug usage, leaving one social group to join another (see Pilkington, 2008). As identified above in the work by Fletcher and Spracklen (2013), those who abstain, for any of a number of reasons, might find certain social roles or opportunities inaccessible to them. Even for those who do partake, difference in stances towards particular drugs or intensities of use may mean that friendship groups may be drawn and fractured by divergent attitudes to drug use and practice (Parker et al., 1998). Amongst a group that readily 
defines their sociality around drinking of alcohol, non-drinkers might be seen to not 'fit in' with the group identity and, as such, be conspicuously marginalised (Niland et al., 2013).

\section{Conclusion}

This chapter has sought to highlight the complex ways in which drug and alcohol consumption, and the feelings, experiences, activities and settings involved, play a significant role in the construction of identity and in sociability between individuals and within groups. By way of conclusion, this final section reflects on the relational, embodied nature of this sociality fostered by alcohol and drug consumption. It argues that a nuanced understanding of the sociality implicit in much substance use is integral to current and future developments in the field.

In the second section of the chapter, I have attempted to draw out some of the ways in which sociality is played out during drug and alcohol consumption. However, it is also interesting to note that across many of these studies the manner in which participants refer to this sociality is tellingly epigrammatic. In many of the empirical studies discussed, reference to fun, 'having a laugh', 'hanging out' (Waitt and Warren 2008), indicate both the complexity and, somewhat contradictory, the banality of drug and alcohol consumption. Rather than vague, ill-defined, descriptors, such terms, in their brevity, indicate the self-evident and taken for granted nature of the social benefits of alcohol and drug use as they appear to those who actually use them. In these accounts, 
an emphasis on being 'in the movement' and an appeal to fun and good times with close friends speaks of the affective and embodied nature of the experience of intoxication.

In their use, alcohol and drugs play an important role in mediating between individual and group identity. It is precisely this duel function, a loss of self on the one hand and the collectively of sociability on the other, that many users find appealing and, it is worth adding, that government backed law and order and health interventions find so problematic to engage with. Intoxication redefines sociality and relationships between individuals, groups and society. We have seen that individuals pursue intoxication as a means of letting go and of losing themselves, that by transgressing social rules and strictures of social control, individuals can bond in groups (Griffin et al., 2009). In my own work on stag tourism (Thurnell-Read, 2011; 2012), alcohol was revealed to provide a vital role in allow individuals to 'let go' and 'cut loose', in doing so becoming part of a group while at the same time, often but not always, flagrantly flouting many wider conventions of social propriety.

In terms of methodology, it is also worth noting that a number of the studies referenced in this chapter employ qualitative methods, involving either ethnographic forms of participant-observation or in-depth semi-structured interviews with individuals or friendship groups in which participants are encouraged to freely elaborate their own accounts of drug and alcohol consumption. Such methodologies have implications for the types of knowledge that can be generated about drink and drugs and the experience 
of those who consumer them. The empirical proximity that these research undertakings have the potential to achieve allows for a greater understanding of the sense of the extraordinary and altered states that intoxication can give rise to. As Shelia Henderson (1999: 40) argues in her discussion of gendered aspects of 1990s rave drug use, 'a whole host of visual, aural and oral stimuli brought crowds of diverse young people together in a sensual social space on a grand scale'. Such studies have shown that drug and alcohol consumption is a social, emotive, affective and embodied activity. Again, the evident need to give due attention to this complexity, and to the subjective and qualitative aspects of drug and alcohol use, suggests that the advances of recent decades need to continue in order to develop a fuller picture of the nature of drug and alcohol use across a range of social and cultural contexts.

As Cameron Duff has argued $(2011 ; 2013$; this volume), there is a need to move beyond overly reified accounts of substance use and instead to work towards understandings of 'assemblages' which place alcohol (or drugs) as active actors in affective networks encompassing users and substances but also bodies, settings, objects and practices. Indeed, while the turn towards the social and the sociable during the 1990s allowed for rich qualitative insights and a move away from simplistic accounts of pathologised 'problem' drug and alcohol use, it seems the current direction of the field of research might further enhance our understanding by deploying exactly the theoretical frameworks that Duff proposes and that have the potential to allow for even more holistic analyses to be made. 
Not wishing to overplay the progress of this field of research, it is worth acknowledging a number of areas that remain relatively underexplored. As no doubt this overview demonstrates, a significant proportion of contemporary research in this field focuses on young people. Perhaps because their identity is seen to be more 'in process' and their social networks, friendships and bonding rituals more in flux and open to adaptation, the drinking and drug taking practices of young adults and adolescents make for enticing research subjects. However, how sociality and identity relate to alcohol and drug consumption in later life or, for that matter, within the family, remain underexplored and largely untheorised (a notable exception being Jayne et al.'s 2011 book exploring alcohol across three generations of the same families). Similarly, the spectacular nature of public displays of drunkenness, or the equally spectacular setting of the rave or nightclub, means that more mundane spaces in which drinking and drug use take place are, again, conspicuously overlooked. Thus, consumption in the home remains methodologically difficult to access.

The fact that our understanding of drug and alcohol consumption remains wedded to conceptualisations of leisure also means that little research has been conducted into drug and alcohol use within the work place. Interestingly, widespread media coverage of comments by British Professor David Nutt linking the global financial crisis with the bravado and risk taking culture brought on by cocaine use of investment bankers in New York and London (Williams, 2013), perhaps provides clues as to future directions the social sciences might take in understanding the social uses of drugs and alcohol 
consumption. While the college campus, the local high street bar, pub or club on a Saturday or the sports ground club house all provide vibrant examples of the roles played by drugs and alcohol in the construction, performance and maintenance of identity, the social and the sociable extend into spaces, times and practices that have still not been the subject of sustained academic inquiry.

\section{References}

Allison, A. (1994) Nightwork: Sexuality, pleasure, and corporate masculinity in a Tokyo hostess club. Chicago: University of Chicago Press.

Anderson, D. Hailu, D. and Klein, A. (2007) Khat Controversy: Stimulating the debate on drugs. Oxford: Berg.

Balsa, A.I., Homer, J.F., French, M.T. and Norton, E.C. (2010) Alcohol Use and Popularity: Social payoffs from conforming to peers behavior, Journal of Research on Adolescence, 21(3): 559-568.

Beccaria, F. and Sande, A. (2003) Drinking Games and Rite of Life Projects: A social comparison of the young people's use of alcohol during the rite of passage to adulthood in Italy and Norway, Young, 11(2): 99-119.

Beckerly, S. and Nuur, S. (2005). A View from the Refugee Camps: New Somali khat use in Kenya', Drug and Alcohol Today, 5(3): 25-27. 
Belackova, V. and Vaccaro, C.A. (2013) "A Friend With Weed is a Friend Indeed": Understanding the relationship between friendship identity and market relations among marijuana users', Journal of Drug Issues, 43(3): 289313.

Blackshaw, T. (2003) Leisure life: Myth, masculinity and modernity. London: Routledge.

Borsari, B. (2004) Drinking Games in The College Environment: A Review, Journal of Alcohol and Drug Education, 48(2): 29-51.

Brown, R. and Gregg, M. (2012) The Pedegogy of Regret: Facebook, binge drinking and young women, Continuum: Journal of Media and Cultural Studies, 26(3): 357-369.

Campbell, H. (2000) The Glass Phallus: Pub(lic) Masculinity and Drinking in Rural New Zealand, Rural Sociology, 65(4): 562-581.

Carrier, N. (2005) Under Any Other Name: The trade and use of khat in the UK, Drugs and Alcohol Today, 5(3): 14-16.

Carrier, N. (2007) Kenyan Khat: The Social Life of a Stimulant. Boston: Brill. 
Chatterton, P. and Holland, R. (2002) Theorising Urban Playscapes: Producing, regulating and consuming youthful nightlife city spaces, Urban Studies, 39(1): 95-116.

Chrzan, J. (2013) Alcohol: Social Drinking in Cultural Context. New York: Routledge.

Crawford, G. (2009). 'Consuming Sport, Consuming Beer: Sport fans, scene, and everyday life', in L.A. Wenner and S.J. Jackson (eds.) Sport, Beer, and Gender: Promotional culture and contemporary social life. Bern: Peter Lang.

Cullen, F. (2010) “Two's Up and Poncing Fags": Young women's smoking, practices, reciprocity and friendship, Gender and Education, 22(5): 491-504.

de Visser, R. and Smith, J.A. (2007) Young Men's Ambivalence Towards Alcohol, Social Science and Medicine, 64(2): 350-362.

Dempster, S. (2011) I Drink, Therefore I'm Man: Gender discourses, alcohol and the construction of British undergraduate masculinity, Gender and Education, 23(5): 635-653.

Driessen, H. (1992) 'Drinking on Masculinity: Alcohol and gender in Andalusia', in Gefou-Madianou, D. (ed.), Alcohol, Gender and Culture. Oxford: Routledge. pp. 71-79. 
Duff, C. (2011) Reassembling (Social) Contexts: New directions for a sociology of drugs, International Journal of Drug Policy, 22(6): 404-406.

Duff, C. (2013) The Social Life of Drugs, International Journal of Drug Policy, 24(3): 167-172.

Fletcher, T. and Spracklen, K. (2013) Cricket, drinking and Exclusion of British Pakistani Muslims?, Ethnic and Racial Studies, 37(8): 1310-1327.

Foster, K. and Spencer, D. (2013) "It's Just a Social Thing": Drug use, friendship and borderwork among marginalized young people', International Journal of Drug Policy, 24(3): 223-230.

Fry, M-L. (2011) Seeking the Pleasure Zone: Understanding young adult's intoxication culture, Australian Marketing Journal, 19(1): 65-70.

Griffin C, Bengry-Howell A, Hackley C, Mistral W and Szmigin I (2009) 'Every time I do it I absolutely annihilate myself': Loss of (self-)consciousness and loss of memory in young people's drinking narratives. Sociology 43(3): 457476.

Griffiths, P., Gossops, S., Wickenden, S., Dunworth, J., Harris, K. and Lloyd, C. (1997) A Transactional Pattern of Drug Use: Qat (khat) in the UK. The British Journal of Psychiatry, 170: 281-284. 
Hackley, C., Bengry-Howell, A., Griffin, C., Mistral, W., Szmigin, I. and Hackley, R. (2013) Young Adults and 'Binge' Drinking: A Bakhtinian analysis, Journal of Marketing Management, 29(7): 933-949.

Henderson, S. (1999) 'Drugs and Culture: The question of gender' in N. South (ed.) Drugs: Cultures, Controls and Everyday Life. London: SAGE.

Hunt G. and Evans, K. (2008) "The Great Unmentionable": Exploring the pleasures and benefits of Ecstasy from the perspective of drug users, Drugs, 15(4): 329-349.

Hunt, G., MacKenzie, K. and Joe-Laidler, K. (2005) 'Alcohol and Masculinitiy: The case of ethnic youth gangs', in T.W. Wilson (ed.), Drinking Cultures: Alcohol and identity. Oxford: Berg.

Hunt, G., Moloney, M. and Kristen, E. (2010) Youth, Drugs, and Nightlife. New York: Routledge.

Jayne, M., Holloway, S. and Valentine, G. (2006) 'Drunk and Disorderly: Alcohol, urban life and public space', Progress in Human Geography, 30(4): $451-468$.

Jayne, M., Valentine, G. and Holloway, S.L. (2011) Alcohol, Drinking, Drunkenness: (Dis)orderly spaces. Farnham: Ashgate. 
Joseph, J. (2012) Around the boundary: Alcohol and older CaribbeanCanadian men, Leisure Studies, 31(2): 147-163.

Josiam, B. M., Hobson, J. S. P., Dietrich, U. C., and Smeaton, G. (1998) An analysis of the sexual, alcohol and drug related behavioural patterns of students on spring break, Tourism Management, 19 (6): 501-13.

Kuntsche, E., Knibbe, G. and Engels, R. (2005) Why Do Young People Drink? A review of drinking motives, Clinical Psychology Review, 25(7):841-861.

Leyshon M (2008) 'We're stuck in the corner': Young Women, Embodiment and Drinking in the Countryside, Drugs: Education, Prevention and Policy, 15(3): 276-289.

MacLean, S. and Moore, D. (2014) "Hyped Up": Assemblages of alcohol, excitement and violence for outer-suburban young adults in the inner-city at night, International Journal of Drug Policy, Online First.

Malbon, B. (1999) Clubbing: Dancing, ecstasy and vitality. London: Routledge.

Measham, F. and Brain, K. (2005) Bing drinking, British alcohol policy and the new culture of intoxication, Crime, Media and Culture, 1(3): 262-282. 
Montemurro, B. and McClure, B. (2005) Changing Gender Norms for Alcohol Consumption: Social drinking and lowered inhibitions at Bachelorette parties, Sex Roles, 52(6): 279-288.

Moore, K. and Miller, S. (2005) Living the High Life: The role of drug taking in young people's lives, Drugs and Alcohol Today, 5(2): 29-32.

Niland, P., Lyons, A.C., Goodwin, I. and Hutton, F. (2013). "Everyone Can Loosen Up and Get a Bit of a Buzz On": Young adults, alcohol and friendship practices. International Journal of Drug Policy, 24(6): 530-537.

Nordgren, J. (2013) The moral entrepreneurship of anti-khat campaigners in Sweden - a critical discourse analysis, Drugs and Alcohol Today, 13(1): 2027.

Osman, F. and Söderbäck, M. (2011) Perceptions of the use of khat among Somali immigrants living in Swedish society, Scandinavian Journal of Public Health, 39(2): 212-219.

Parker, H., Aldrige, J. and Measham, F. (1998) Illegal Leisure: The normalization of adolescent recreational drug use. Hove: Routledge.

Pilkington, H. (2007) Beyond 'Peer Pressure': Rethinking drug use and 'youth culture', International Journal of Drug Policy, 18(3): 213-224. 
Plant, M. and Plant, M. (2006) Binge Britain: Alcohol and the national response. Oxford: Oxford University Press.

Saunders, N. (1996) Ecstasy: Dance, Trance and Transformation. San Francisco: Quick American Archives.

Sheehan, M. and Ridge, D. (2001) "You become really close...you talk about the silly things you did, and we laugh": The Role of Binge Drinking in Female Secondary Students' Lives, Substance Use and Misuse, 36(3): 347-72.

Smith, Oliver. (2014) Contemporary Adulthood and the Night-Time Economy. London: Palgrave Macmillan.

Sönmez, S., Apostolopoulosb, Y., Yuc, C. H., Yangd, S., Mattilae, A. and Yue, L. (2006) Binge Drinking and Casual Sex on Spring Break, Annals of Tourism Research, 33(4): 895-917.

Stepney, M. (2013) British Women's Experiences of Drinking Alcohol: Dynamics of emotional proximity and distance, Emotion, Space and Society, 10: $105-112$.

Taylor, S. (2008) Outside the outsiders: Media representations of drug use, Probation Journal, 55(4): 369-387. 
Thornton, K. (1995) Club Cultures: Music, media and subcultural capital. Cambridge: Polity.

Thurnell-Read, T. (2012) 'What Happens on Tour': The premarital stag tour, homosocial bonding and male friendship, Men and Masculinities, 15 (3): 249270.

Thurnell-Read, T. (2011) 'Off the Leash and Out of Control': Masculinities and embodiment in Eastern European stag tourism', Sociology, 45(6): 977-991.

Tomsen, S. (1997) A Top Night: Social protest, Masculinity and the Culture of Drinking Violence, British Journal of Criminology, 37(1): 90-102.

Tutenges, S. and Sandberg, S. (2013) Intoxication Stories: The characteristics, context and implications of drinking stories among Danish Youth', International Journal of Drug Policy, 24(6): 538-544.

Vander Ven, T. (2011) Getting Wasted: Why college students drink too much and party too hard. New York: New York University Press.

Waitt G, Jessop L and Gorman-Murray A (2011) 'The guys in there just expect to be laid': Embodied and Gendered Socio-spatial Practices of a 'Night Out' in Wollongong, Australia, Gender, Place and Culture, 18(2): 255-275. 
Waitt, G. and Warren, A. (2008) 'Talking shit over a brew after a good session with your mates': Surfing, space and masculinity, Australian Geographer, 39(3):353-365.

Williams, R. (2013) 'Financial meltdown was caused by too many bankers taking cocaine, says former government drugs tsar Prof David Nutt', The Sunday Times, $15^{\text {th }}$ April 2013.

Wilson, T. (2005) Drinking Cultures. New York: Berg.

Wolburg, J. and Treise, D. (2004) 'Drinking Rituals Among the Heaviest Drinkers: College Student Binge Drinkers and Alcoholics, in C. Otnes and T. Lowrey (eds.), Contemporary Consumption Rituals: A research anthology. Mahwah: Lawrence Erlbaum. pp. 3-20.

Zhou, J., O'Brien, S. and Heim, D. (2013). Alcohol Consumption in Sportspeople: The role of social cohesion, identity and happiness, International Review of Sociology of Sport, Online First. 